\title{
Una nueva interpretación de «El cacique de Turmequé» de Gertrudis Gómez de Avellaneda.
}

Palabras claves: leyenda, crónica, tiempo histórico, re-escritura.

\section{Introducción}

En «El cacique de Turmequé» escrito en 1860 y publicado en 1871, Gertrudis Gómez de Avellaneda vuelve a narrar la crónica de Juan Rodríguez Freyre, El carnero o conquista y descubrimiento del Nuevo Reino de Granada, compuesta entre 1636-1638 y publicada por primera vez en Bogotá en 1859. En esta obra, la escritora redefine la «política masculina» del gobierno virreinal; haciendo hincapié en los pormenores familiares y privados de los oficiales coloniales distinguidos. Avellaneda se sirve de las fuentes históricas con lujo y detalle: batallas, hazañas heroicas, masacres y plagas. Pero a la vez, recrea la historia humana, escondida y perdida, en episodios creados por su propia imaginación y sus convicciones sociales. En estas escenas ficticias la autora se concentra mucho más que los cronistas en las relaciones de comprensión, amistad y amor, los que difícilmente daban cabida en las primeras crónicas bélicas de estrategias militares o en relatos más tardíos o informativos sobre culturas autóctonas. Al contrario de lo que hacían los escritores españoles de su época que ensalzaban la figura de los conquistadores, subestimando el valor y la importancia de la cultura precolombina, la cubana se opone a este modelo, dirigiendo su atención al cacique de Turmequé y su amante, Estrella. De esta manera, manipula el tiempo histórico, para proponer al público español del XIX otra versión de la conquista, una que no era la de los vencedores, sino la de los vencidos; distanciándose del discurso dominante de su época. 
A través de este ensayo se mostrará que Gertrudis Gómez de Avellaneda a través de su leyenda, demuestra su determinación y espíritu libre; creando personajes femeninos fuertes y comprometidos con el derecho de decidir su propio destino. Además, presenta una visión de la conquista de Nueva Granada distinta del historiador y también diferente a la que los lectores españoles de la época estaban acostumbrados a leer. En contraposición, en «El cacique de Turmequé» mucho más que en la crónica original, se exploran los motivos relacionados con el poder de los personajes involucrados en la doble intriga amorosa y política: el adúltero fiscal Orozco y su esposa; la infiel Estrella y su marido, el capitán; y don Diego de Torres, cacique de Turmequé, hijo de un conquistador y una princesa indígena. Como bien ha señalado Picon Garfield, de la crónica de Rodríguez Freyle, Avellaneda amplía los episodios novelescos y amorosos, y adopta los personajes y sucesos principales a los cuales añade la figura ficticia de la negra esclava de Estrella (Picon Garfield, 1993: 100). También altera ciertos hechos significantes de los cuatro capítulos de El carnero y ofrece comentarios inexistentes en el texto original.

\section{El cacique de Turmequé}

Tanto en la crónica de Juan Rodríguez Freyre, como en la leyenda de Avellaneda, se nos narra la historia del nombramiento de Juan Bautista Monzón como Visitador General del Nuevo Reino de Granada para juzgar las actuaciones de la Audiencia y de los encomenderos ${ }^{1}$. El escritor reseña de manera bastante rápida los primeros treinta años de la historia del Nuevo Reino, para detenerse principalmente en los sucesos contemporáneos, sobre todo los que corresponden a la primera etapa de su vida, es decir, al último cuarto del siglo XVI y a los primeros años del siglo XVII. Freyle se muestra muy poco benévolo e inclusivamente hostil hacia visitadores y jueces, hasta el punto de calificarlos de «polilla de esta tierra y menoscabo de ella» (Rodríguez Freyle, 1979: 206). Al igual que ocurrió en el resto del continente, la Audiencia se vio acompañada de un grupo muy especial de funcionarios y licenciados en leyes que, fieles al espíritu de su profesión, incrementaron las querellas y pusieron litigios a la orden del día, con lo cual, se abrió un amplio campo a las diversas formas de corrupción, particularmente de extorsión y soborno. Muchas

1 Juan Bautista Monzón puso preso a Lope Díex Aux de Armendáriz, combatió la corrupción de los Oidores de la Real Audiencia, decretó medidas contra el fraude en los impuestos y el salvajismo contra los indígenas, salvó del destierro al Cacique Turmequé. El Fiscal de la Audiencia, Miguel de Orozco conspiró contra Bautista Monzón acusándole de aliarse con Turmequé para favorecer la invasión británica a Santa Fé. 
páginas de El carnero giran en torno a los conflictos suscitados por las visitas, y la lucha por el poder económico y político entre las diversas facciones locales. En este sentido, en el texto del escritor neogranadino se nos revelan las disputas políticas y sociales que perturbaron constantemente la sociedad colonial hasta comienzos del siglo XVII y que deben interpretarse a la luz de la polaridad entre un Estado centralizador y los esfuerzos de la casta de los encomenderos para mantener las prerrogativas que se derivaban de la conquista.

Como anota certeramente Gónzalez Echevarría, usando la historia como punto de partida narrativo, Freyle compuso una serie de anécdotas y exempla para revelar las dimensiones de la vida en la colonia que otras historias ignoraron o menoscabaron (González Echevarría, 2006: 185). Según las circunstancias del relato, el narrador irrumpe brevemente en el discurso de la narración para moralizar acerca de tópicos o vicios muy diversos (sobre los daños de la embriaguez, la perniciosa hermosura de la mujer, la maledicencia, la codicia, el tiempo, el poder, etc.). En el discurso del neogranadino se yuxtaponen episodios reales con «casos» narrados en su mayor parte en la tercera persona; confrontando los hechos públicos con los privados ${ }^{2}$. Freyle ilustra su concepción de historia, que distingue de la del poeta, y de la función de su obra que es la de dar a conocer la verdad; justifica además su particular elección de los casos atribuyendo a éstos y a su escrito en general un fin moral y ejemplar. La dimensión autobiográfica de El carnero se observa en los muchos comentarios sobre su vida y sus experiencias, como también en sus innumerables observaciones y opiniones cáusticas sobre la naturaleza de la sociedad y la humanidad. El autor remite constantemente a los autos de la Real Audiencia; otras veces él ha sido testigo presencial o los ha recogido de otros espectadores. Sin embargo, pronto se desentiende El carnero del rigor cronológico y del dato fidedigno sumergiéndose en una empresa en la que la historia-sólo en el capítulo XI su autor decide autodenominarse «cronista» - sirve de telón de fondo a los eventos sociales, es decir, a los relatos en los que la brujería, la violencia o el interés político constituyen la verdadera materia del asunto. La obra de Freyle es una crónica en la medida en la que el dato histórico es preponderante, no obstante la alternancia de secuencias tanto históricas como folclóricas, sociales y picarescas, otorgan al relato una sugestiva intención novelística que lo ameniza. Aunque toma ciertos caracteres de la realidad, no se detiene sobre periodos históricos de relieve $\mathrm{y}$, a veces con demasiada rapidez, pasa por encima un evento de enorme importancia (Arango, 2011: 164).

2 Desde el punto de vista historiográfico, Freyle se basa en las crónicas de fray Pedro Simón, el padre Juan de Castellanos y en la extensa tradición oral americana. 
Al igual que el escritor neogranadino, Gómez de Avellaneda también afirma su deber de «no alterar la exactitud de los hechos» contados en la crónica, pero a diferencia del cronista, la escritora cubana no presume de que la perspectiva del historiador sea siempre objetiva, y declara que: «La crónica refiere — sin salir garante de que sean ciertos todos los pormenores del suceso». En este sentido, la autora parece así imitar los modelos de la tradición dominante, pero a la vez rompe con los valores hegemónicos; estableciendo su «auto-definición» y en suma, diferenciándose de la creación de sus iguales masculinos (Picon Garfield 1993: 103). La propuesta constante de cambio se encuentra codificada en la manipulación de recursos narrativos que emplea en su discurso. Como confirman Sandra Gilbert y Susan Gubar, la estrategia de las mujeres consiste en revisar, destruir y reconstruir las imágenes femeninas heredadas de la literatura masculina y moldeadas según los parámetros de los hombres, prototipo que todas las escritoras del siglo XIX se veían obligadas a adoptar como punto de partida (Gilbert y Gubar, 1979: 76). La historia de la cubana sigue las pautas del texto de Rodríguez Freyle, aunque en algunos aspectos se separa de la anécdota inicial, con lo cual, justifica sus cambios. Avellaneda prefiere hacer una «recreación» de las crónicas de Indias; representando uno de aquellos tumultuosos cuadros del Nuevo Mundo, en el que el heroísmo y la perversidad chocaban de continuo. La cubana narra un hecho que ocurrió con frecuencia en América; la explotación de un natural de sus tierras en favor de los encomenderos, utilizando como pretexto el acusarle de encabezar un levantamiento de indios. De esta manera, cuenta la historia de Diego de Torres, y como fue acusado de encabezar un movimiento popular, siendo finalmente perseguido, capturado y condenado a muerte. ${ }^{3}$

Para el cronista Rodríguez Freyle, todo el conflicto que se dio en 1570, se explicaba a partir de los celos de la esposa del fiscal y las intrigas de su amante, que lo llevaron a la perdición. Estos eventos son narrados con gran picardía, a manera de chismes y de diversión de tipo rabeliano, y condimentados con toques moralistas. La feroz antipatía del autor contra las mujeres - lleva implícita una coartada, evidente en el objetivo de sus ataques: no son todas las mujeres las que reciben las diatribas, sino apenas una selecta parte compuesta por las más «bellas». El presunto moralista deja ver de inmediato su verdadero propósito, al punto de que lo que parecía una furiosa admonición se convierte pronto en una encendida erotomanía. El libertino asoma sus fauces con el dicterio con que responde a la indiferencia de las hermosas, únicas criaturas

3 Diego de Torres fue acusado de ayudar a los ingleses en la preparación de una invasión a los territorios de Nueva Granada, hecho por el cual fue encarcelado. Más tarde, don Diego viajó a España y terminó sus días bajo la protección del rey Felipe II. 
a las que se enfrenta, ya que las feas no le interesan y las despacha de entrada con aire pícaro con la frase: «cada olla tiene su cobertura» (Rodríguez Freyle, 1979: 167). El discurso sobre el género femenino en este caso guarda una clara afinidad con la visión maniquea que divide a la mujer, sin términos medios, en bona mulier o mala mulier. En el caso de Estrella podemos identificar por lo menos tres tópicos que configuran el paradigma de la mala mulier, como son: su incontinente sexualidad, su astucia al engaño y su papel como agente en la seducción y caída del hombre en la depravación moral. Ya en el capítulo V de El carnero, tras una curiosa interpretación del libro del Génesis, el autor hace un largo paralelo de las mujeres «malas sabandijas, de casta de víboras» que a lo largo de la historia y de la ficción gracias al «garabatillo» de su sexo han sabido cavar la fosa de muchas empresas, causas y, como no, de hombres ilustres: ahí están para probarlo nada menos que Eva, Betsabé, la hija del Faraón, Dalila, Helena de Troya y Florinda. El ataque de Freyle contra el género femenino adopta con frecuencia un talante socarrón e incluso hiriente, mostrando en todo caso su aversión hacia las jóvenes, diciendo:

Siempre me topo con una mujer hermosa que me dé en qué entender. Grandes males han causado en el mundo las mujeres hermosas, y sin ir más lejos, miren la primera, que sin duda fue la más linda, como amasada de las manos de Dios, ¿qué tal quedó el mundo por ella? De la confesión de Adán, su marido, se puede tomar, respondió a Dios: "Señor, la mujer que me disteis, esa me despeñó" ¡Que de ellas podía yo agora ensartar tres Evas! Pero quédense dice Fray Antonio de Guevara, obispo de Mondoñedo, que la hermosura y la locura andan siempre juntas; y yo digo que Dios me libre de las mujeres que se olvidan de la honra y no miran al ¡que dirán!, porque perdida la vergüenza, se perdió todo (Rodríguez Freyle, 1979: 258).

Efectivamente, el escritor cita la conocida historia de la desafortunada conversación que sostiene la mujer con el diablo, arremetiendo así contra el género femenino. Valiéndose de algunos comentarios misóginos, la joven es presentada como la dominadora del mundo, la gobernante de los hombres, sometidos a ella por el poder de su pecado y de su mentira. En otra ocasión comenta:

¿Qué diferencia hay entre mandar las mujeres la república, o mandar a los varones que mandan las repúblicas? Las mujeres comúnmente son las que mandan el mundo; las que se sientan en los tribunales y condenan y sentencian al justo y sueltan al 
culpado; las que ponen y quitan leyes y ejercitan con rigor las sentencias; las que reciben dones presentes, y hacen procesos falsos" (Rodríguez Freyle, 1979: 329).

En contraposición a este discurso, Avellaneda se aleja del discurso oficial; la autora no compartía así los comentarios misóginos; ofreciendo al lector una visión más objetiva de los personajes femeninos. La leyenda de la escritora es una donde los ideales románticos están a flor de piel puesto que se ofrece una visión poética del Nuevo Mundo, una apasionada defensa de la mujer, una exaltación de los sentimientos, un canto a la libertad y una condena por tanto, de toda tiranía. Desde una óptica completamente diferente a la del escritor de Santa Fe, intenta acercarse de forma comprensiva a la que fue la desencadenante del problema. En la leyenda de la cubana, Estrella es un personaje bien definido y estructurado cuya característica más sobresaliente es la belleza y la fantasía. El narrador omnisciente conoce y se adueña del personaje, desmenuza sus sentimientos y angustias, profundiza en su mundo interior, compartiendo sus penas y compadeciéndose de su situación:

Estrella, en nuestro concepto, no era una persona positivamente mala, sino que tenía-como otras muchas mujeres-la desgracia de haberse quedado incompleta, acaso por la falta de acertada educación. Viva de fantasía, vehemente de carácter, impresionable por temperamento, carecía en cambio, de exactitud en el raciocinio, de fijeza en las ideas, de profundidad en los efectos (Gómez de Avellaneda, 1976: 43).

Para la escritora, es la falta de instrucción y preparación de Estrella lo que la hace desviarse de la normativa moral de la época. La autora toma conciencia de las injusticias contra su propio sexo y llega a la conclusión de que es la sociedad la que pervierte al ser humano. Incluso al darle un nombre que sugiere "luz" parece separarse así de los prejuicios del cronista. Según Gómez de Avellaneda, es la fantasía de la mujer y la carencia de «exactitud en el raciocinio, fijeza de ideas y falta de profundidad en los afectos», lo que le lleva a un caos emocional al no poder reconciliar su ideal amoroso con la realidad que imagina; produciendo consecuentemente conflictos, dilemas y luchas internas. En este sentido, y como bien ha perfilado Alexander R. Selimov, por el modo en que instrumentaliza los motivos tradicionales en la configuración de los personajes femeninos, así como las características de su lenguaje, su visión del mundo y su ideología, la prosa narrativa de la escritora, tanto de ambientación contemporánea, como de asunto histórico, se inscribe plenamente en la corriente 
romántica: «Avellaneda no sólo expone los dilemas individuales del "yo" en el contexto de su rebelión cósmica, sino que aplica la técnica romántica a la textualización de una aguda crítica a la sociedad contemporánea, arremetiendo contra la imagen doméstica de la mujer» (Selimov, 2003: 79).

Otro aspecto en el que Avellaneda difiere de Freyle, es en la imagen que proyecta del don Diego de Torres. Como bien comenta Luis Fernando Restrepo, la visión del mestizo belicoso e inmoral del discurso colonial es reemplazado por una idealización romántica en la obra de la cubana (Restrepo, 2010: 15). Rodríguez Freyle narra la prisión y sentencia a muerte de don Diego y su posterior huida a España. Para el autor de El carnero, el adulterio del fiscal Orozco es sintomático de la corrupción del gobierno. El cacique como sujeto colonial era visto como una fuerza incapaz de una verdadera conciencia; su voluntad era deficiente debido a las inclinaciones de una sangre supuestamente corrupta. En este sentido, el cronista neogranadino cuenta en su narración la vida de la época, pero no denuncia los problemas sociales; éstos los considera de orden moral o de voluntad divina. Manuel Antonio Arango comenta que la condición social relacionada directamente con los abusos contra los indios de parte de las autoridades españolas, y de los grandes terratenientes criollos o extranjeros, los ignora por completo (Arango, 2011: 165-166). Por el contrario, en el texto de la escritora cubana, el mestizo es un galán que admiran las mujeres al verlo pasar por las calles de Santa Fé:

Con dificultad se podría encontrar otro hombre en quien se mezclan tan armónicamente los más nobles rasgos de los hijos de la Europa meridional, con lo característicos de las castas superiores americanas, constituyéndole un tipo magnífico, que no vacilamos en calificar como el bello ideal de los mestizos (Gómez de Avellaneda, 1976: 44-45).

Efectivamente, Avellaneda re-escribe estos capítulos de la crónica sobre el subalterno mestizo, injustamente perseguido por las autoridades. La autora en este caso interpreta ideológicamente los sentimientos de los autóctonos a merced del imperio y la actitud abusiva de los colonos; su discurso toma matices de censura en la crítica al poder español que subyace en el contexto global de la leyenda. A la información sobre el hijo del conquistador don Juan de Torres y la princesa Catalina de Moyachoque, hija del soberano de Tunja, añade la autora otro calificativo específicamente racial que no figura en la crónica original: el cacique era: «gallarda postura de aquel príncipe indiano», de « frente altiva y espaciosa, hecha al parecer expresamente para ostentar una corona» (44). De este modo, la autora 
subvierte los valores dominantes de la sociedad de su tiempo, al representar al sujeto indígena con características diametralmente opuestas a las representaciones de la ideología colonial. A través de la trama, la autora construye un personaje alternativo, ya que don Diego de Torres ha tenido la excepcional experiencia para un indígena, el hecho de tener acceso a la cultura europea en lo que se refiere a las lecturas y formación académica; resaltando su educación en las letras castellanas y conocimientos de la lengua y costumbres muiscas; su proclamación como cacique y sus viajes a España. Don Diego al inscribirse en «cacique cristiano» buscaba legitimar su dominio tanto en la tradición muisca como en la jurídica hispánica, y su apelación al amparo real como indio agravado y buen cristiano ponía en tela de juicio los principios que legitimaban la soberanía imperial. En este sentido, su mestizaje le confiere una cierta autoridad sobre los dos mundos, convirtiéndole metafóricamente en un intérprete o enlace entre ellos.

En cuanto a la ficción de Freyle, las demandas sociales de justicia de don Diego no tienen lugar en esta historia colonial, ni tampoco su disputa por el cacicazgo se encuentra en El carnero, pues el escritor comienza la narración del cacique tras la llegada del visitador Monzón ${ }^{4}$. Es decir, se salta el primer viaje de don Diego a España y, por consiguiente, no se menciona la Relación de agravios (1578) de don Diego de Torres, donde se refería a los múltiples abusos que sufrían los indígenas por parte de los encomenderos y las autoridades coloniales neogranadinas. Como criollo terrateniente, a Rodríguez Freyle no parece interesarle mucho resaltar las querellas que levantó don Diego por el maltrato de los indios ni el reclamo de los mestizos por el cacicazgo, aunque probablemente sí tendría información de los pleitos de don Diego y Alonso de Silva (Restrepo, 2010: 27). Lo que encontramos, en cambio, en la crónica del escritor de Nueva Granada son recuerdos encubridores, los cuales prestan atención a los aspectos secundarios. Por ejemplo, se narra con gran detalle cómo escapó de la prisión don Diego de Torres. Ve al cacique como «un mestizo, hombre rico y gran jinete», mas nunca lo reconoce como letrado, como un escritor que conocía a la perfección tanto la cultura virreinal como la peninsular. A este respecto Luis Fernando Restrepo señala lo siguiente: «En El carnero, la conciencia moral del Nuevo Reino es función reservada para los criollos, no para los mestizos, ni para los indígenas» (Restrepo, 2010: 27). Por el contrario, Avellaneda se sirve de la información sobre el rumor espurio de la sublevación

4 En El carnero, Freyle introduce dos capítulos en los que trata la historia civil de los chibchas, desfigurando completamente la realidad. Así pues, echa por tierra los dos imperios muisca y tunjano, y cree que los caciques eran los reyes de este suelo, pero nunca menciona los abusos cometidos contra ellos. 
indígena encabezada por el cacique; pero a diferencia de la crónica, atribuye la carta al mismo cacique, haciendo de él una figura activamente subversiva, quien por añadidura censura al gobierno colonial.

Ahora bien, en la versión de la cubana, Estrella es asesinada por su propio esposo; convirtiéndose en una figura trágica que muere al haber reafirmado su libertad e integridad de espíritu. De esta manera, la protagonista se inscribe perfectamente en el modelo romántico, y al mismo tiempo guarda paralelo con el prototipo de heroína clásica; encarnando el papel del amor imposible. Por el contrario, don Diego marcha a España, pero es perseguido por el viudo de Estrella con el fin de vengar la deshonra de la alianza del cacique con ella. Movido por la compasión, decide perdonar al cacique, y éste termina sus días bajo la especial protección del rey Felipe II, monarca que dio al mestizo el título de «Caballerizo Menor». La escritora, rompe así con la historia, ya que nada concuerda con la realidad, con el hecho de que don Diego de Torres después de presentar el Memorial de agravios, se quedó unos años más en España, donde se casó con doña Juana de Oropesa y siguió alegando sus derechos del cacicazgo y defendiéndose en el proceso que se le hizo por el levantamiento, conspiración y botín, hasta los últimos días de su vida.

\section{Conclusión}

Gertrudis Gómez de Avellaneda no sólo se rebeló contra los cánones establecidos por la sociedad a través de sus experiencias personales, sino que también mostró en sus escritos su inconformismo frente a una sociedad convencional. En «El cacique de Turmequé» creó figuras trágicas que reafirman su libertad e integridad del espíritu violando los dogmas y reglas de la comunidad de su tiempo. La escritora incurre una y otra vez en la ficción, recreando su propia historia y, sobre todo, presentando los conflictos amorosos interraciales, en el desgarro sentimental del choque de culturas, en el enfrentamiento entre la pasión, la seducción, la violencia y la atracción amorosa. A diferencia de la crónica novelesca de Rodríguez Freyle que trata de enmarcar la obra dentro de una concepción de la historia universal de claro origen cristiano-medieval y de una serie de consideraciones filosófico- morales; la narrativa de la cubana rompe de completo con este modelo. Parece ser que Avellaneda en su novela corta «El cacique de Turmequé» cuestiona la historia, y en cierto sentido reescribe la crónica de Freyle, con el claro propósito de ofrecer al lector peninsular una versión de la conquista no tan romántica o patriótica como la que estaban acostumbrados a leer los lectores españoles de la época. 


\section{Bibliografía}

Alzate Cadavid, C. (1999): Desviación y verdad. La re-escritura en Arenas y la Avellaneda. Boulder: Society of Spanish American Studies.

Arango, M. A. (2011): Proceso bistórico-social en la literatura de los primeros cronistas de la conquista de América. Nueva York: Peter Lang.

Bravo Villasante, C. (1973): Gertrudis Gómez de Avellaneda. Madrid: Fundación Universitaria Española.

Cabrera, R. (1981): Homenaje a Getrudis Gómez de Avellaneda. Memorias del simposio en el centenario de su muerte. Miami: Ediciones Universal.

Friede, J. (1965): Descubrimiento y conquista del Nuevo Reino de Granada, Bogotá: Ediciones Lerner.

Gilbert, S. (1979): The Madwoman in the attic: The woman writer and the Nineteenth Century Literary Imagination. New Haven: Yale Univesity Press.

Goic, C. (1991): Historia y crítica de la literatura bispanoamericana. II. Del Romanticismo al Modernismo. Barcelona: Editorial Crítica.

Gómez de Avellaneda, G. (1976): Obra selecta. Mary Cruz (ed.). Caracas: Biblioteca Ayacucho.

González Ascorra, M. I. (1997): La evolución de la conciencia femenina a través de las novelas de Gertrudis Gómez de Avellaneda, Soledad Acosta de Samper y Mercedes Cabello de Carboneda. Nueva York: Peter Lang.

González de Echevarría, R. (2006): Historia de la Literatura Hispanoamericana. I. Del Descubrimiento al Modernismo. Madrid: Editorial Gredos.

Montero, S. (2005): La Avellaneda bajo sospecba. La Habana: Editorial Letras Cubanas.

Orjuela, H. (2004): Crónicas y cronistas de la Nueva Granada. Bogotá: Editora Guadalupe.

Pastor, B. (2002): El discurso de Getrudis Gómez de Avellaneda: Identidad femenina y otredad. Alicante: Publicaciones de la Universidad de Alicante.

Picon Garfield, E. (1993): Poder y sexualidad en El discurso de Gertrudis Gómez de Avellaneda. Amsterdam: Rodopi.

Restrepo, L. F. (2010): «El cacique de Turmequé o los agravios de la memoria». En: Cuadernos de Literatura. 28.14-33.

Rodriguez Freyle, J. (1979): El carnero. Dario Achuri Valenzuela (ed.). Caracas: Biblioteca Ayacucho. 
Selimov, A. (2003): De la Ilustración al Modernismo: la poética de la cultura romántica en el discurso de Gertrudis Gómez de Avellaneda. Boulder: Society of Spanish and Spanish-American Studies.

Showalter, E. (1984): A Literature of their Own. British Women Novelists from Brontë to Lessing. Nueva York: Virago Press.

VV.AA. (1981): Homenaje a Gertrudis Gómez de Avellaneda. Memorias del simposio en el centenario de muerte. Gladys Zaldívar (ed.). Miami: Ediciones Universal.

VV.AA. (1999): Inés de Hinojosa. Historia de una transgresora. Isabel Rodríguez Vergara (ed.). Medellín: Editorial Universidad de Antioquía.

VV.AA. (1980): Nueva bistoria de Colombia. Colombia indígena, conquista y colonia. Barcelona: Editorial Planeta. 


\section{María Luisa Pérez Bernardo}

University of Dallas

\section{A new interpretation of «El cacique de Turmequé» by Gertrudis Gómez de Avellaneda}

Keywords: Legend, chronicle, historical time, re-write.

Gertrudis Gómez de Avellaneda is remembered for her controversial and progressive beliefs. She established a reputation early in her career as a talented writer whose unconventional behavior was as well known as her works. During her lifetime, Avellaneda enjoyed literary and commercial success in several genres, including poetry, drama, essays, and lengends. In the legend «El cacique de Tumequé» written in 1860 and published in 1871, Gertrudis Gómez de Avellaneda re-interpretes Juan Rodríguez Freyle's El carnero o conquista y descubrimiento del Nuevo Reino de Granada (1636-1638). Through this essay it will be displayed how Avellaneda with «The cacique of Turmequé» presents a vision of Nueva Granada distinct to that of the chronicler Juan Rodríguez Freyle. In this way, the female writer manipulates historical time, to propose to the Spanish public of the 19th century another version of the conquest, one that was not that of the victors, but of the vanquished; distancing herself from the dominant discourse of her time. In «El cacique de Tumequé», Avellaneda challenges the political power of the colonial era that positioned women as inferior human beings. In her narrative, she breaks away from the established order, especially against the misogynist remarks from El carnero, a chronicle that consistently criticized and ridiculed women. Gómez de Avellaneda's work deconstructs the social and political institutions that emphasized the idea that women were intellectually subordinate. Moreover, in «El cacique de Turmequé» she defendes the dignity of the indigenous population, by reaffirming their integrity and liberty in the colonial society. 
María Luisa Pérez Bernardo

University of Dallas

\section{Nova interpretacija El cacique de Turmequé Gertrudis Gómez de Avellaneda}

Ključne besede: legenda, kronika, zgodovinski čas, ponovni zapis

Gertrudis Gómez Avellaneda je znana po svojih kontroverznih in naprednih prepričanjih. Že na začetku kariere se je uveljavila kot nadarjena pisateljica, postala je znana tako po pisanju kot tudi po nekonvencionalnem obnašanju. Kot avtorica poezije, gledaliških iger, esejev in legend je že za časa svojega življenja doživela velik uspeh. Legenda El cacique de Turmequé je bila napisana leta 1860 in objavljena 1871 , v njej pa avtorica reinterpretira delo Juana Rodrígueza Freyleja El carnero o conquista y descubrimiento del nuevoo reino de Granada (1636-1638). V tem prispevku je prikazano, kako v delu El cacique de Turmequé Avellaneda predstavi drugačen pogled na Nueva Granado od tistega, ki ga odraža omenjeni pisec kronik. Pisateljica se poigrava z zgodovinskim časom, da bi španskim bralcem predstavila drugačno podobo konkviste, podobo poražencev, in se distancira od diskurza, prevladujočega v njenem času. Avellaneda izziva politično oblast v kolonialnem obdobju, ki je ženske imela za nižja bitja, razbija ustaljen red in napada mizogine opazke v El carneru, kroniki, ki vztrajno kritizira in smeši ženske. Delo Gertrudis Gomez de Avellaneda pomeni dekonstrukcijo družbenih in političnih ustanov, ki poudarjajo, da so ženske intelektualno podrejene. Poleg tega pa v El cacique de Turmequé brani dostojanstvo staroselskega prebivalstva ter potrjuje njegovo integriteto in svobodo v kolonialni družbi. 